\title{
Antecedents of organizational creativity: drivers, barriers or both? ${ }^{1}$
}

\author{
Annika Blomberg \\ University of Turku, Turku School of Economics; 28101 Pori, Finland \\ anjoma@utu.fi \\ Tomi Kallio \\ University of Turku, Turku School of Economics \\ tomi.kallio@utu.fi \\ Heikki Pohjanpää \\ Realmachinery Oy; 37550 Lempäälä, Finland \\ heikki.pohjanpaa@realmachinery.fi
}

\begin{abstract}
This paper reviews academic journal articles and scholarly books focusing on organizational creativity and constructs a schematic representation of the antecedents of organizational creativity, i.e. of the associated drivers and barriers. The literature on organizational creativity is reviewed using a traditional review technique. The focus is especially on more recent developments of the discourse, and therefore this work can be labeled as a stateof-the-art review. The review shows that drivers have clearly been studied more extensively than barriers. It was also recognized that the predominant approach among organizational creativity scholars is to dichotomize the factors influencing organizational creativity, more specifically to discuss the antecedents of creativity mostly from the viewpoint of drivers. In some cases, the antecedents are discussed from the perspective of barriers, but only rarely has it been recognized that the very same factor may either enhance or inhibit creativity. In this paper, such factors are called 'either-or factors'. The paper suggests that the organizational creativity discourse should acknowledge that it is not enough to understand what enhances organizational creativity but also which kind of issues inhibit it and, especially, which factors may work either against or toward creativity under different circumstances. The review suggests that the majority of factors are most likely either-or by nature, although it has been overlooked in the discourse due to the dichotomizing tendency.
\end{abstract}

Keywords. Organizational Creativity, Organization Studies, Creativity, Literature Review.

\footnotetext{
'A previous version of this paper was published as a part of the first author's PhD Thesis at Turku School of Economics at University of Turku, Pori, Finland.
} 


\section{Introduction and purpose of paper}

Fierce competition, the turbulent economic situation and a greater speed of change have made creativity a highly sought-after capability for business organizations. Instead of relying on long-range strategies, organizations need to be able to anticipate and react to fast changes and take advantage of the unknown. Therefore, it is not enough for organizations to recruit creative individuals; instead the whole organization needs to be adaptive, flexible and innovative. These requirements have brought the notion of 'organizational creativity' to the centre of managerial interests in the past few years. Along the increase in managerial interest, organizational creativity has increasingly attracted the interest of scholars from several different social sciences fields. In fact, a simple search via Scopus (www.elsevier.com) showed that the number of peer-reviewed studies mentioning 'organizational creativity' in all search fields was 31 in 1990, 357 in 2000, and 2,430 in 2010 (see Appendix 1). Organizational creativity is thus emerging as a distinct area of academic inquiry, although the speed of emergence of new publications hints at the potential danger of fragmentation. There is thus a need for studies synthesizing current knowledge. Among the few existing examples is Andriopoulos' (2001) article 'Determinants of organizational creativity: a literature review,' which has been cited widely. Although this study was a useful attempt toward reviewing the drivers of organizational creativity, it is quite clearly outdated as a literature review, especially considering the pace of academic publishing on the topic over the last fifteen years.

More recently, Klijn and Tomic (2010) analyzed the factors that could be considered drivers of organizational creativity and surveyed major creativity models, mediators, and enhancers from a psychological perspective. This paper focuses explicitly on what the authors call enhancers, i.e., drivers, however our analysis is not constrained to the psychological perspective. In addition, unlike Klijn and Tomic (2010), this paper reviews not only the drivers of but also the barriers hindering organizational creativity. A few years later, Anderson et al.'s (2014) state-of-the-science review on creativity and innovation in organizations proposed a guiding framework for future research in the domain. Anderson et al.'s (2014) review covered a wide range of drivers of organizational creativity although its coverage of barriers to organizational creativity was not equally extensive. The extensive coverage of drivers and a very scarce interest in barriers is even more notable in the case of empirical studies on organizational creativity. This trend could be reflective of an optimistic belief that by adding in enough drivers, organizational creativity is enhanced. This is, however, not the case because even only one barrier to creativity, for instance a constant lack of time, may very effectively inhibit creativity, even in the presence of many drivers. The so-called positivity-negativity asymmetry effect, which refers to the human tendency to be more strongly influenced by negative events than by positive ones, exists in almost all psychological domains such as social relationships, emotions, and learning (Baumeister et al., 2001). Similarly, a single or a few barriers to organizational creativity are likely to cast an effect that can overcome the influence of several drivers. Moreover, several of the barriers to organizational creativity are related to factors that necessarily exist in an organization, such as climate, leadership, or time pressures, and inevitably work either against or toward creativity. Therefore, 
to complement the current knowledge on determinants of organizational creativity, this paper proposes that a more thorough understanding of the drivers of and, especially, the barriers to organizational creativity is needed. Moreover, to overcome the optimistic focus on drivers in finding ways to enhance creativity, a more elaborated perspective on the understanding of the antecedents of organizational creativity is provided.

Thus, the purpose of this paper is to review the antecedents of organizational creativity as presented in academic journal articles and scholarly books and deepen the theoretical understanding of the nature of antecedents of organizational creativity. First, organizational creativity as a topic of study is introduced and a few basic models of organizational creativity are briefly described. Second, the paper elaborates on the antecedents of organizational creativity identified in the reviewed studies. Then a theoretical perspective is taken and it is discussed how antecedents, i.e., drivers and barriers, of organizational creativity are typically theorized in the organizational creativity discourse [1]. It is suggested that instead of showing excessive interest in the drivers of organizational creativity, it should be recognized that many, if not most, of the factors might in fact act as drivers or barriers depending on the context and situation. We call the factors, which can have either enhancing or inhibiting influences on creativity, as either-or factors and conclude that the organizational creativity discourse should acknowledge that it is not enough to know and understand what enhances organizational creativity but also which kind of issues inhibit it and, especially, which factors may work either against or toward creativity under different circumstances. Finally, the conclusions are presented and the findings and limitations discussed.

\section{Organizational creativity as a topic of study}

Themes related to creativity have been studied systematically ever since the 1950s. The foci of creativity related studies have been on individual-centered psychometric perspectives, while the social and organizational designs and settings where creativity takes place have received much less attention. Authors interested in these social settings see the domination of individual perspectives as an important limitation (see, e.g., Styhre and Sundgren, 2005; Shalley and Zhou, 2008). Consequently, creativity scholars such as Csikszentmihalyi (1994) urge the need for widening the scope of what is perceived as the process of creativity. Specifically, Csikszentmihalyi (1994( suggests adopting a systemic perspective that includes not just the individual but also the cultural and social contexts.

Within organizational studies, creativity has been recognized as an important organizational element in several seminal works (see, e.g., Mintzberg, 1979; Morgan, 1986). However, while these classic studies recognize the importance of creativity per se, they nevertheless perceive it only as one factor among others. Therefore, as Sundgren and Styhre (2007, p. 219) have put it, "an important step in understanding creativity in an organizational context is to take a more holistic approach and use the concept of organizational creativity." What distinguishes organizational creativity research from general creativity research is that it is not interested in creativity in the 
arts, short-term problem-solving tasks conducted in behavioral laboratories, children's creativity, or helping individuals to think more creatively, etc. (cf. Shalley and Zhou, 2008 , p. 3-4). It is interested in creativity in the context of a work organization and leans on an understanding of creativity as a broader phenomenon than simply as an individual thought process. It seems that the majority of scholars contributing to the organizational creativity discourse share a general understanding of the definition of the very phenomenon itself. This predominant definition is the one presented by Woodman et al. (1993, p. 293), who define organizational creativity as "the creation of a valuable, useful new product, service, idea, procedure, or process by individuals working together in a complex social system."

Usually, innovation and creativity are considered to be closely related and, sometimes, the concepts are even used interchangeably (see, e.g., Amar and Juneja, 2008). A widely agreed upon view distinguishes creativity from innovation in that creativity refers to production of ideas, whereas innovation refers to the successful implementation of ideas (Amabile, 1996; McLean, 2005). The relevance of organizational creativity studies is often justified in terms of it acting as a precursor for innovation (see. e.g., Amabile et al., 1996; Styhre and Sundgren, 2005), and this paper takes a similar stance. Although there are only few empirical studies on the relationship between creativity and innovation (see, e.g., Mohamed and Rickards, 1996; Bharadwaj and Menon, 2000; Sohn and Jung, 2010), it has been found that a creative climate (Mohamed and Rickards, 1996; Sohn and Jung, 2010) and formal creativity-enhancing approaches and structures (Bharadwaj and Menon, 2000) contribute to the innovation performance of a firm. However, in this paper, the interest is primarily in organizational creativity itself, and therefore, the literature on innovation and organizational innovation (see Crossan and Apaydin, 2010 for a review) has not been included in the review. Moreover, this paper leans on a broader conceptualization of organizational creativity (Woodman et al., 1993) instead of seeing it only as the production or generation of ideas (cf. Amabile, 1996).

According to Shalley and Zhou (2008), the two main theoretical models of organizational creativity are the componential model created by Amabile (e.g., 1988) and the interactionist model of Woodman et al. (1993). According to Amabile's (e.g., 1988) componential model of creativity, creativity takes place at the intersection of expertise or domain-specific skills, motivation, and creative thinking skills. Amabile $(1983 ; 1988 ; 1996 ; 1997)$ was among the first scholars who attempted to widen the scope of creativity research from the individual level to the social level and, eventually, to the organizational level. In a similar vein, Woodman et al. (1993) proposed one of the first multilevel models by linking individual-, group-, and organization-level variables to creative outcomes. Both the componential and the interactionist models explore the multidimensional nature of organizational creativity. To elaborate further, the models of Amabile $(1983 ; 1988 ; 1996 ; 1997)$ and Woodman et al. (1993) illustrate that individual creativity is a complex phenomenon influenced by multiple individual-level factors, as well as contextual and environmental factors. Even though both models stress the role of contextual factors at different levels, Woodman et al.'s (1993) model emphasizes on the interaction between the person and the situation and, importantly, on various influences across levels.

Cross-level influences on creativity are essential in identifying the attributes that 
enhance or constrain organizational creativity. The interactionist model investigates creativity at different levels with social and contextual influences. For example, individual characteristics such as cognitive abilities, personality, and motivation are defined as factors. Group characteristics such as size, diversity, roles, cohesiveness, and problem solving are group-level determinants of organizational creativity. Lastly, organization characteristics such as culture, resources, and strategies are presented as examples of organization-level influences (Woodman et al., 1993). Overall, the model is based on the notion that creative individuals, groups, and organizations are inputs that are transformed in various ways by the process and the situation, which includes both drivers of and barriers to creativity at all levels of analysis (Woodman et al., 1993). In this paper, the idea set forth by Woodman et al. (1993) is adopted in pursuing to analysis of the antecedents of organizational creativity.

\section{Data collection and analysis}

This paper reviews the fast growing body of literature on organizational creativity using a traditional review technique and focusing on articles published during or after 2000 (Jesson et al., 2011), complemented with a snowballing technique (Ridley, 2012) to track studies that were published prior to 2000 but were widely cited and thus relevant to the field. A special emphasis is put on more recent developments of the discourse, as it was around the year 2000, when the interest in organizational creativity started to grow notably (see Appendix 1). Thus, this work can be labeled as a state-of-the-art review, the purpose of which is to provide a contemporary, comprehensive overview of a particular topic (see Jesson et al., 2011; Lucarelli and Berg, 2011). In this case, it enables to focus particularly on studies published after Andriopoulos's (2001) widely cited review and, thus, to concentrate on more recent developments in the discourse, while still taking into account some older, yet influential studies.

In August and September 2014, a search of three electronic databases [2] was conducted to search for journal articles dealing with organizational creativity. The search phrase benchmarked from Blomberg (2014) was 'organi?atio* AND creativity' [3]. The search focused on peer-reviewed, scholarly articles published between January 2000 and September 2014. The abstracts of the articles gathered in the search were read by two authors of the paper to decide whether they actually discussed organizational creativity, and those that did were read in full. To complement the database search, a snowballing technique (Ridley, 2012) was used to track older articles (published prior to 2000) that are widely cited and, thus, relevant to the field but not included in the database search. They were included in the review because they were considered central to the understanding and development of the research domain.

When reading and analyzing the material, a thematic analysis was applied. A theme represents a patterned meaning within the empirical material and reveals something relevant to the research question (Braun \& Clarke 2006). Thus, thematization allows for meaningful, systematic, and rigorous interpretation of collected data (Saunders et al., 2003). The analysis proceeded in the following way: First, the material was 
carefully read and commonly recurring themes related to antecedents of organizational creativity were identified through a pattern-matching technique. Second, the themes were revised to make sure there was enough material to support them. Next, the formed themes were classed into four levels of analysis based on Woodman et al.'s (1993) study of organizational creativity, which was used by Anderson et al. (2014) as well in their review. Consequently, the analysis is divided into the following levels: i) individual, ii) group/team, iii) organization, and iv) macro [4]. Lastly, we identified inconsistencies and gaps in the extant literature concerning antecedents of organizational creativity.

\section{Drivers and barriers in organizational creativity}

In this section, the recognized drivers of and barriers to organizational creativity are explicated on four levels: individual, group, organization and macro. The subsections follow the same order. Each level is further divided to cover the individual themes formulated during the pattern-matching process, and each theme comprises individual factors.

Scholars have found several attributes that facilitate organizational creativity (drivers) on all levels of analysis, but they have paid much less attention to the barriers. The following subsections cover the major themes on the abovementioned four levels, as identified in the reviewed articles. Studies focusing on the individual, group, or macro level are much fewer in number than those concentrating on the organizational level. A relatively large number of studies focus on multiple levels simultaneously, for instance, on the group and organizational levels. Nevertheless, it was possible to position the factors discussed in these articles in terms of the four specific levels. In general, the levels of analysis are relatively explicit, but some themes and factors do overlap slightly.

\subsection{Individual level}

Organizations and groups comprise individuals, and therefore, individual creativity is often considered the basic element of organizational creativity. Thus, it is somewhat surprising that fewer studies focus specifically on the individual level than on organizational level. Individual creativity has been studied exhaustively in earlier studies on creativity, and is therefore no longer considered to be of great interest, as several authors (see Björkman, 2004; Klijn and Tomic, 2010; De Stobbeleir et al., 2011) have pointed out. However, four major themes covering the individual aspect of organizational creativity were identified in the reviewed articles: i) 'selfmanagement' factors such as self-efficacy, self-regulation, and self-concordant goals, ii) motivation, iii) mood and affect, iv) knowledge, knowledge acquisition and its accumulation through workshops, feedback, and internal/external relationships, for example. These themes are explicated below.

The first theme covers what can be called self-management factors and their effect on creative performance. The terms used in the studies include self-efficacy, self-esteem, self-regulation, creative identity, and self-concordant goals, which have been found to have a positive link with creative outcomes (see Axtell et al., 2000; Tierney and 
Farmer, 2002, 2011; Chong and Ma, 2010; De Stobbeleir et al., 2011; Ejaz et al., 2011; Mathisen, 2011; Richter et al., 2012). In other words, a strong belief in one's own actions and creative capability is positively related to individual creativity, whereas low self-esteem and self-censorship may inhibit individual creativity (Williams, 2002). The fact that self-management factors are considered an important driver of organizational creativity highlights the importance of giving employees a role that is autonomous and carries enough responsibility to facilitate selfmanagement (Axtell et al., 2000). These self-management factors are also connected to the second theme, motivation.

Intrinsic motivation is traditionally recognized as an important element of creativity, whereas extrinsic rewards are found to be detrimental to creativity (Amabile, 1983; Baer et al., 2003). The role of extrinsic motivation, and especially achieving the right combination of intrinsic and extrinsic motivation was discussed in the reviewed studies (see, e.g., Mumford, 2000; Baer et al., 2003; McLean, 2005; Sundgren, Selart et al., 2005, Griffin et al., 2009). Put in other words, there is a general agreement that intrinsic motivation is a necessary driver of creativity, and extrinsic rewards are usually considered as barriers to creativity (Amabile, 1983). However, in the reviewed articles, extrinsic rewards and extrinsic motivation were widely discussed from the viewpoint of being drivers (Mumford, 2000; Walton, 2003; Sundgren, Selart et al., 2005; McLean, 2005; Griffin et al., 2009), in that for instance, informative feedback and evaluation actually increase intrinsic motivation and creativity (Zhou, 1998; Sundgren, Selart et al., 2005). Thus, there is general agreement that motivation is a significant factor, but there are varying views on the roles and the right balance of intrinsic and extrinsic motivation and their influence on creativity.

The third theme to emerge was mood or affect, referring to both emotion and mood. Positive affect has been found to enhance individual creativity (see Amabile et al., 2005; Adler and Obstfeld, 2007; Klijn and Tomic, 2010; Baron and Tang, 2011). Affect influences the creative process in three ways. First, it is integrally linked with motivation. Second, creativity is particularly susceptible to affective influences due to the cognitive variations that stimulate it. (Amabile et al., 2005.) Third, individuals typically recall mood-congruent information, and more information tends to be recalled during a good mood (Walton, 2003; Elsbach and Hargadon, 2006). Some scholars argue that there may be a link between negative affect and creativity (e.g., George and Zhou, 2002; 2007), but their results are less consistent than in the case of positive affect (Amabile et al., 2005; Klijn and Tomic, 2010). A negative mood in general can be considered as a barrier to creativity (Amabile et al., 2005), although Elsbach and Hargadon (2006), for instance, argue that it may also work as a driver when employees perceive that creativity is recognized and rewarded in their organization. Elsbach and Hargadon (2006) further suggest that negative affect may serve to motivate creative work when workload pressures are low, but when the pressure is high, positive affect may be required to stimulate the flow of creative thoughts.

The fourth theme, knowledge and experience of the field are typically perceived as necessary preconditions for creativity (see, e.g., Amabile, 1996; Weisberg, 1999; Mumford, 2000; Egan, 2005; Sundgren and Styhre, 2007). Several scholars discuss different ways of accumulating knowledge, such as workshops (e.g., Birdi, 2005), 
feedback (e.g., De Stobbeleir et al., 2011; Zhou and George, 2001), and internal/external relationships (e.g., Madjar, 2005; 2008; Perry-Smith, 2006). However, previous knowledge may also inhibit organizational creativity in terms of causing fixedness and rigidity in an individual's thinking (Woodman et al., 1993; Klijn and Tomic, 2010) or as it may result in more habitual thinking (Ford, 1996).

\subsection{Group level}

Even fewer articles focus explicitly on the group level of organizational creativity than on the individual level. However, four major themes emerged: i) diversity, ii) group management, iii) group climate and culture, and iv) creativity-enhancing techniques.

The first theme, diversity covers the skills, functional or hierarchical positions, knowledge, and background of the group members (see, e.g., Walton, 2003; Egan, 2005; Bunduchi, 2009; Burbiel, 2009; Hemlin, 2009; Andriopoulos and Lewis, 2010; Yoon et al., 2010; Richter et al., 2012). Groups rich in diversity have been found to be more creative, whereas homogeneous groups, whose members possess overlapping skills, are less likely to develop creative ideas. Diversity can, however, also negatively influence creativity. In some cases, it causes misinterpretation of other participants' ideas, which is a risk, especially in the virtual team context. Geographic dispersion, too, can exacerbate the group members' differences and cause feelings of isolation or disappointment (Chamakiotis et al., 2013.)

The second theme, group management, includes factors such as the group's selfmanagement (Axtell et al., 2000; Isaksen and Lauer, 2002; Kylén and Shani, 2002; Björkman, 2004), group leadership (Hemlin, 2009; Chamakiotis et al., 2013), organizational encouragement (Castiglione, 2008; Hemlin, 2009), support for innovation (Axtell et al., 2000; Hemlin, 2009), and feedback (Zhou and George, 2001; Hemlin, 2009). Group management implies that the group should be able to manage itself effectively, whereas organization-level management should be appropriate in terms of allowing and facilitating the group's work. Potential barriers to creativity here are the dominance of some members, which may reduce other members' creativity (Chamakiotis et al., 2013).

The third theme, creativity-enhancing group culture and climate, requires the group members to trust each other (Andriopoulos, 2001; Sadi and Al-Dubaisi, 2008; Hemlin, 2009); communicate well in the group (Andriopoulos, 2001; Al-Beraidi and Rickards, 2003; Egan, 2005; Sadi and Al-Dubaisi, 2008; Hemlin, 2009; Misra, 2011); have a sense of belonging, cohesiveness, and commitment (Al-Beraidi and Rickards, 2003; Egan, 2005; Hemlin, 2009; Misra, 2011); and have a positive attitude toward other group members (Egan, 2005). It is equally important to have clear objectives for group work (Al-Beraidi and Rickards, 2003; Egan, 2005), an open environment (e.g., Andriopoulos, 2001; Hemlin, 2009), a supportive learning culture (Thompson 2003; Yoon et al. 2010), psychological safety (Andriopoulos, 2001; Hemlin, 2009; Kessel et al., 2012), and shared vision and goals (Al-Beraidi and Rickards, 2003). Creativity is enhanced naturally if group members are motivated (Amabile, 1983), but, additionally, adequate pressure and demand are needed to spark the motivation of the team (West, 2004; Hemlin, 2009). Furthermore, a climate that allows productive 
conflict between group members is a driver of group creativity (Egan, 2005; Isaksen and Ekvall, 2010; He et al., 2014). However, too much disagreement or need for conformity, or the wrong kind of conflict may act as a barrier (Pech, 2001; Egan, 2005; Isaksen and Ekvall, 2010; He et al., 2014). Other factors that potentially block creative group climate include negative attitudes, a controlling or constraining environment, lack of psychological safety, and time or expectation pressures (Amabile, 1996; Egan, 2005; Kessel et al., 2012).

The fourth theme, creativity-enhancing techniques, has been covered extensively. It differs from the three previous themes in that it focuses mostly on creativity understood as the generation of ideas and multiple perspectives, whereas the other three themes focus on creativity more broadly. Brainstorming (see McFadzean, 2000; Al-Beraidi and Rickards, 2003; Thompson, 2003; Walton, 2003; Egan, 2005; Litchfield, 2008) in particular is discussed widely and is generally used to generate ideas and multiple perspectives from multiple members (Thompson, 2003; Egan, 2005). However, Walton (2003), Egan (2005) and Elsbach and Hargadon (2006) argue that brainstorming does not always produce favorable outcomes and that the sessions are not necessarily effective at yielding creative outputs. Despite the related problems, however, most participants in brainstorming sessions generally believe it to be a very effective strategy for enhancing group creativity (Egan, 2005). Few other creativity-enhancing techniques were also discussed, such as lateral thinking (Butler, 2010) and creative problem solving techniques (McFadzean, 2000). Some scholars suggest that ideation would benefit from ready-made templates or structures, concluding that structure-consistent ideas outperform random ideas in terms of their creativeness (Goldenberg and Mazursky, 2008).

\subsection{Organization level}

Organization-level creativity has received the most interest compared to the individual, group, and macro levels. Moreover, organization-level factors are discussed in several articles dealing with multiple levels in the same analysis. Therefore, it is only natural that views pertaining to the organizational level of creativity are the most diverse. At the organizational level, the following themes emerged: i) management and leadership, ii) knowledge, iii) resources, iv) structure and systems, v) spatial/physical dimensions, and vi) organizational culture and climate.

The first theme, management and leadership, associated with enhancing creativity, is one of the most common themes in the reviewed articles. Management-related factors influencing organizational creativity include providing employees with sufficient freedom and autonomy (Daymon, 2000; Mumford, 2000; Sundgren, Selart et al., 2005; Moultrie and Young, 2009; Andersen and Kragh, 2015), appropriate resources (Epstein et al., 2013), job design (Elsbach and Hargadon, 2006; Amar and Juneja, 2008), supervisory support (e.g., Sundgren, Selart et al., 2005; Wang and Casimir, 2007; DiLiello and Houghton, 2008; Andersen and Kragh, 2015;), establishing creativity-enhancing cultural practices (Isaksen and Ekvall, 2010; Epstein et al., 2013), and coping with paradoxes related to managing creativity (Andriopoulos and 
Lewis, 2010; Knight and Harvey, 2015). For instance, managers are required to encourage individuals to think outside the box, while simultaneously maintaining a shared direction for the creative work (Andersen and Kragh, 2015). Although freedom and autonomy were discussed mostly from the viewpoint of being drivers (Amabile, 1997; Daymon, 2000; Sundgren, Selart et al., 2005;), it was noted that finding a suitable balance between freedom and control depending on the task is important because too much freedom and autonomy may become a barrier to creativity (Mumford, 2000; Bunduchi, 2009).

Numerous articles focus also on leadership and, specifically, leadership styles (see, e.g., Andersen, 2000; Farmer et al., 2003; Sundgren, Selart et al., 2005; Politis, 2005; Wang and Casimir, 2007; Pryor et al., 2010). Transformational (Al-Beraidi and Rickards, 2003; Shin and Zhou, 2003; Wang and Rode, 2010) or participative and democratic (Andriopoulos, 2001; Somech, 2006; Mathisen et al., 2012) leadership styles are important drivers of organizational creativity because leadership style encourages employee creativity directly and influences the climate and culture of an organization, especially in small organizations (Somech, 2006; Mathisen et al., 2012). However, there is empirical evidence that this applies to Western cultures, whereas in Asian cultures, a more authoritative leadership style is needed to enhance creativity (Zhou and Su, 2010). Moreover, the leader's emotional intelligence was found to be conducive to employee creativity (Zhou and George, 2003; Rego et al., 2007; Castro et al., 2012). Although leadership- and management-related issues were mostly discussed as drivers of creativity in the reviewed articles, it can be assumed that management and leadership styles that fail to fulfill the aforementioned criteria would act as a potential barrier to creativity. The studies mentioned that a management that promotes people who conform to the organization's traditions and behave in ways considered appropriate could inhibit creativity because this kind of leadership encourages conformity rather than creativity (Pech, 2001).

Organization-level knowledge is the second theme, covering aspects such as organizational learning, which refers to the organization's capability and willingness to learn and acquire new knowledge (see, e.g., Borghini, 2005; Basadur and Gelade, 2006; Amar and Juneja, 2008; Tajeddini, 2009; Shahin and Zeinali, 2010) knowledge combination (see, e.g., Umemoto et al., 2004; Borghini, 2005; Sundgren and Styhre, 2007); and cross-fertilization of knowledge (see, e.g., Umemoto et al., 2004 McLean, 2005; Madjar and Ortiz-Walters, 2008; Mahmoud-Jouini and Charue-Duboc, 2008). Although knowledge is a crucial element of organizational creativity, it may be a barrier in some cases (Sundgren, Dimenäs et al., 2005; Mahmoud-Jouini and CharueDuboc, 2008): as a form of power in an organization, knowledge is not shared easily.

It is commonly agreed that the production of creative outputs requires sufficient resources such as time and money (see, e.g., Andriopoulos and Gotsi, 2000; Andriopoulos, 2001; Barrett et al., 2005), which comprise the third theme. It should be noted that sufficiency enhances creativity, but excess may lead to inefficiency (Mumford, 2000; Bunduchi, 2009). Insufficient resources in terms of time, funds, and expertise constitute a common barrier to creativity (e.g., Sadi and Al-Dubaisi, 2008). Moreover, excessive workload pressure is a common barrier to creativity (Amabile, 1996; Hemlin, 2009).

The fourth theme covers an organization's structure and systems (see, e.g., 
Andriopoulos and Gotsi, 2000; Andriopoulos, 2001; Martins \& Terblanche 2003; Chang and Chiang, 2008; Chong and Ma, 2010). Factors such as rigidity of an organization's structure (see, e.g., Walton, 2003; Sundgren, Dimenäs et al., 2005; Mahmoud-Jouini and Charue-Duboc, 2008), formalization and a strong hierarchy (see, e.g., McLean, 2005; Wang and Casimir, 2007) act as barriers to organizational creativity. In hierarchical organizations, especially, employees in positions of low power tend to adopt a more careful and reactive style, and show less creativity (Walton, 2003). Therefore, creative talent is usually considered to flourish in a loosely structured working environment with more flexibility and fewer restrictions (Pryor et al., 2010). In general, an organic type of structure is more likely to enhance creative capabilities (see, e.g., Cooper, 2005; DiLiello and Houghton, 2008; Wood et al., 2011). However, there are studies with contradictory findings (Brown et al., 2010; Bissola and Imperatori, 2011; Çokpekin and Knudsen, 2012), arguing for the importance of rules and structure for creativity. For instance, Brown et al. (2010) in their study of architects concluded that to become more creative, the studied architects used many facilitative, yet regulatory mechanisms, activities, standards, and ideals, which suggests that although the discourse emphasizes freedom, such freedom needs to be structured.

A few articles discuss the spatial and/or physical factors that either facilitate or hinder creativity (Haner, 2005; Sadi and Al-Dubaisi, 2008; Magadley and Birdi, 2009; Martens, 2011; Sadi and Sailer, 2011; Epstein et al., 2013). These factors comprise the fifth theme. According to the literature, in facilitating creativity, the most important aspect of designing a physical space is finding the optimal balance between space for communication and space for concentration (Haner, 2005; Sailer, 2011). Spatial settings that are noisy, too crowded, or in which an employee is not able to control the amount of interaction or privacy, can hinder creativity (Martens, 2011).

The sixth theme, which includes matters concerning the organizational climate and culture, is discussed extensively in the reviewed literature. Although many scholars make a clear distinction between climate and culture (Ahmed 1998; Andriopoulos, 2001; Isaksen and Lauer, 2002; Isaksen and Ekvall, 2010), the terms are often used interchangeably (McLean, 2005). Consequently, a few of the related factors, too, are referred to interchangeably, albeit with the same apparent meaning. A multitude of characteristics of organizational climate and culture have been found to drive organizational creativity. These include autonomy (see, e.g., Daymon, 2000; Mumford, 2000; Sundgren, Selart et al., 2005), challenge (see, e.g., Moultrie and Young, 2009; Isaksen and Ekvall, 2010), collaboration and free information flows (see, e.g., Mumford, 2000; Andriopoulos, 2001; Sundgren, Dimenäs et al., 2005), freedom (see, e.g., Moultrie and Young, 2009; Isaksen and Ekvall, 2010;), free exchange of ideas (see, e.g., Mumford, 2000; McLean, 2005; Sundgren, Dimenäs et al., 2005), knowledge sharing and management (see, e.g., Lapierre and Giroux, 2003; Basadur and Gelade, 2006; Schepers and Berg, 2006), encouragement of creativity (see, e.g., Martins \& Terblanche, 2003; Barrett et al., 2005; Sundgren, Selart et al., 2005), and high participation rates (see, e.g., Andriopoulos, 2001; McLean, 2005; Schepers and Berg, 2006). Similarly important characteristics are support for ideas (see, e.g., McLean, 2005; Moultrie and Young, 2009; Isaksen and Ekvall, 2010), trust (see, e.g., Barrett et al., 2005; Moultrie and Young, 2009; Isaksen and Ekvall, 2010), 
dynamism/liveliness (see, e.g., Moultrie and Young, 2009), diversity (see, e.g., Barrett et al. 2005; McLean 2005), playfulness/humor (see, e.g., Moultrie and Young, 2009; Isaksen and Ekvall, 2010; Lang and Lee, 2010), risk taking (see, e.g., Barrett et al., 2005; Moultrie and Young, 2009; Isaksen and Ekvall, 2010), time for ideation (see, e.g., Mumford, 2000; Barrett et al., 2005; Moultrie and Young, 2009; Isaksen and Ekvall, 2010), shared vision and open-mindedness (see, e.g., Andriopoulos and Gotsi, 2005; Tajeddini, 2009), and room for debate/conflicting views (see, e.g., McLean, 2005; Moultrie and Young, 2009; Mainemelis, 2010; Isaksen and Ekvall, 2010).

An organizational climate or culture devoid of the abovementioned attributes may constitute a barrier to organizational creativity (Martins \& Terblanche, 2003; Mostafa, 2005; Mostafa and El-Masry, 2008; Sadi and Al-Dubaisi, 2008). The presence of too much or too little of an attribute such as challenge (see, e.g., Elsbach and Hargadon, 2006) may be a barrier as well. Other related barriers include a willingness to maintain the status quo, high need for conformity, unwillingness to take risks, and rigidity (Pech, 2001; Mostafa and El-Masry, 2008; Sadi and Al-Dubaisi, 2008; Unsworth and Clegg, 2010).

\subsection{Macro level}

The macro level refers to aspects that are external to an individual organization, such as situational or environmental factors. Only a handful of articles explicitly discuss the macro-level factors that influence organizational creativity.

The enhancing factors identified include a stable political environment that favors innovation, sufficient market potential, and an adequate distribution and communication infrastructure and legal environment (Wood et al., 2011). Furthermore, regional cultural diversity and openness to immigration (BaycanLevent, 2010), and a national cultural environment promoting change, risk-taking, and curiosity are conducive to organizational creativity (Khandwalla and Mehta, 2004; Mostafa, 2005; Mostafa and El-Masry, 2008; Zhou et al., 2008). A few papers discuss the differences in creativity between Asian and Western cultures (Erez and Nouri, 2010; Morris and Leung, 2010; Zhou and Su, 2010), concluding that Western social norms tend to place more value on novelty, whereas Eastern norms value usefulness over novelty (Erez and Nouri, 2010; Morris and Leung, 2010). The macrolevel barriers discussed explicitly concern the effects of national culture and corporate acquisition on creativity (Mostafa, 2005; Mostafa and El-Masry 2008; Hempel and Sue-Chan, 2010). Acquisitions may inhibit employee creativity in the acquired organization (Christensen, 2006), and a national culture that favors conformity and has different rules for men and women may be a barrier to organizational creativity (Mostafa, 2005; Mostafa and El-Masry, 2008 Hempel and Sue-Chan, 2010).

\section{Drivers and barriers: beyond dichotomization}

As discussed in the previous section, several drivers of organizational creativity can 
be listed on each level of analysis from the individual to the macro, while considerably fewer barriers were recognized. The notable interest in drivers, and the more limited interest in barriers, could be a reflection of an optimistic belief that the strength of drivers can overcome any potential barriers. However, as already suggested in the paper, this alluring idea might not materialize in practice given that there is a human tendency to be more strongly influenced by negative than by positive issues (cf. Baumeister et al., 2001). Even more importantly, the dichotomizing tendency - that is, the tendency to approach the antecedents of organizational creativity respectively either as drivers or as barriers - is problematic because it fails to acknowledge that the very same factors may actually cast different, sometimes even contradictory, influences on organizational creativity. The dichotomizing tendency might also have to do with the human tendency to look for order and certainty (Tetenbaum, 1998). Therefore, looking at an antecedent's one-directional effect and ignoring that it might have an opposing effect under different circumstances is an easy and appealing option for a scholar. Presenting certain antecedents only as drivers and informing readers of how creativity is promoted through the selected drivers creates an illusion of certainty in relation to the multifaceted phenomenon of creativity (cf. Andriopoulos, 2003; Andriopoulos and Lewis, 2010). However, based on this review's analysis, scholars should adopt a more holistic perspective and look beyond dichotomies while studying organizational creativity. This paper contributes to the aforementioned aim by demonstrating that in addition to drivers and barriers, there are numerous factors that may be either drivers or barriers depending on the circumstances. In this paper, these factors are called either-or factors (see Figure 1).

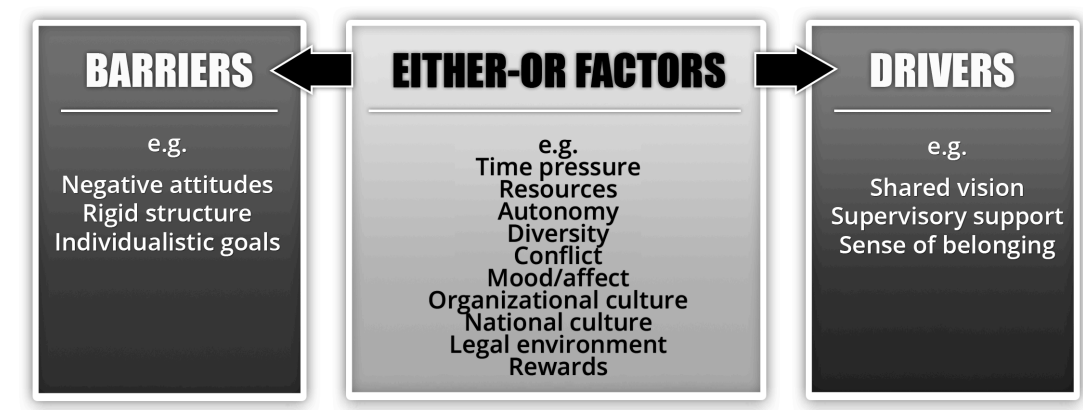

Fig. 1. Examples of barriers to, drivers and, either-or factors of organizational creativity

The fact that under different circumstances the same factors might be either drivers or barriers was already explicitly reflected more than a decade ago by Amabile et al. (2002) in their discussion of the effect of time pressure on creativity under different conditions. According to Amabile et al. (2002), time pressure can act as a driver of creativity in case the employees can focus on the task and consider the task meaningful, whereas it can act as a barrier in case the task is fragmented, employees are often distracted, and the task does not feel meaningful. Some other scholars have, accordingly, discussed the contradicting or paradoxical influences of certain antecedents of organizational creativity, such as diversity and coherence (BassettJones, 2005; Andriopoulos and Lewis, 2010), time and workload pressure (Baer and 
Oldham, 2006; Elsbach and Hargadon, 2006), mood and affect (George and Zhou, 2002; Amabile et al., 2005), organizational culture (Martins \& Terblance, 2003) and rewards (Baer et al., 2003).

Given that Amabile et al. (2002), among others, explicitly brought up the either-or nature of factors affecting organizational creativity in their widely cited study, it is, nevertheless, surprising how little attention this important aspect has received from scholars. Although there are studies that recognize the different, or even contradictory, roles of factors and discuss them accordingly (see, e.g.,; Zhou and George, 2001; George and Zhou, 2002; Baer et al., 2003; Martins \& Terblanche, 2003; Bassett-Jones, 2005; Baer and Oldham, 2006; Elsbach and Hargadon, 2006; Andriopoulos and Lewis, 2010;), the predominant approach in the organizational creativity discourse is to perceive factors from a simple dichotomous perspective and focus on the driver perspective. However, it is only logical to assume that numerous factors dealt with as drivers of organizational creativity in extant studies and discussed earlier in this article could easily work as barriers (and vice versa). Accordingly, a more careful look at the drivers and the barriers recognized in this review should reveal that the very same factors might, depending on the circumstances, act either as drivers or barriers. The role of factors can vary owing to different individual, group, or organizational settings; situational or contextual aspects; or differences in the form or phase of the creative process, which draws from different psychological resources (Cropley and Cropley, 2013). As an illustrative example, other than the one provided by Amabile et al. (2002), one can think resources, for instance.

It is widely recognized that the production of creative outputs requires sufficient resources (see, e.g., Andriopoulos and Gotsi, 2000; Andriopoulos, 2001; Barrett et al., 2005). The difference between the resources currently needed and the total resources available is referred to as 'organizational slack'. In a relatively stable environment, too much organizational slack represents static inefficiency. However, slack can act as a shock absorber in a dynamic market that requires innovation and change, providing opportunities for experimentation (Bunduchi, 2009). Accordingly, too few or too many resources may constitute a barrier, whereas the right amount may work as a driver of organizational creativity. The same logic applies to several other factors such as autonomy, diversity, and conflict as illustrated in Figure 1.

Based on this paper's analysis, it can be argued that many antecedents of organizational creativity are paradoxical by nature (cf. Andriopoulos, 2003; Andriopoulos and Lewis, 2010). The concept of paradox refers to the contradiction of interrelated elements, such as opposing perspectives or contradicting demands (Lewis, 2000). In the case of antecedents of organizational creativity, it means that many antecedents might even have opposing effects on creativity depending on the circumstances. In addition to resources, mood or affect is an excellent example of such an antecedent as it has been studied quite extensively, yet conclusions concerning the relationship between mood/affect and creativity are still partial and even contradictory (Amabile et al., 2005; Klijn and Tomic, 2010). Autonomy and diversity seem to function similarly to resources in relation to organizational creativity, in that they are conducive to creativity until there is too much of them. Too much autonomy easily makes people spend time on tasks that do not align with 
organizational objectives, and too much diversity makes group work difficult and fragmentary (Bassett-Jones, 2005; Andriopoulos \& Lewis, 2010). Naturally, in many cases, the effect also depends on the nature or characteristics of an antecedent. As discussed in this review, certain features of organizational or national culture and certain features of legal environments promote and facilitate creativity while other features hinder it. Similarly, the nature of rewards (e.g. monetary, informative, recognition) or conflict (e.g. related to personal or job-related matters) have different effects on creativity. Although all possible contingencies cannot be covered in a review like this, they should be carefully considered when studying organizational creativity or deciding about practices aimed at facilitating creativity.

The above observations about the either-or factors affecting organizational creativity make it difficult to build an all-encompassing model or a 'global theory' (cf. Borghini, 2005) as the question remains: what is the 'right amount' or the 'right kind' in the case of individual either-or factors? The answer to such a question clearly depends on several case-specific aspects and requires further research.

However, what is said above should not let one make the wrong generalization that all factors affecting organizational creativity would be either-or factors. As Figure 1 illustrates tentatively, some factors such as supervisory support and a sense of belonging are practically always drivers and could thus be considered theoretically as 'one-directional factors'.

Although the review highlights only a handful of barriers, compared to the number of drivers, it seems logical to claim that some of them such as negative attitudes and individualistic goals might in most cases inhibit creativity. Thus, theoretically, they can be considered as one-directional factors, i.e., barriers just as illustrated in Figure 1. This is not to say that it would be impossible to encounter a situation in which an organic structure, for instance, does not act as a driver of organizational creativity. In a similar vein, there may be situations in which a homogenous group is not a barrier. Nevertheless, it seems that at least theoretically, certain factors possess some distinct characteristics that make them act as drivers or barriers in most cases. Understanding all this more thoroughly clearly requires further research focused explicitly on the topic. Based on in-depth studies, it should be possible to draw up, if not an actual 'global theory' (cf. Borghini, 2005), at least certain general rules of the thumb for many, perhaps even for the majority, of questions dealing with either-or factors and one-directional factors of organizational creativity.

\section{Conclusions and limitations}

This paper reports the findings of a review of antecedents of, i.e. drivers of and barriers to organizational creativity. Drivers are factors that have a positive effect on the emergence of organizational creativity, whereas barriers have a negative effect and their presence makes it difficult for the organization to be creative. The paper explicates the recognized drivers of and barriers to organizational creativity on four levels: individual, group, organization, and macro.

It seems from the review that individual and group-level creativity has attracted less interest, while organization-level studies have received the most interest. Moreover, 
several studies focus on how organizational culture and climate, knowledge, leadership, and management, for example, facilitate organizational creativity. At the same time, there are very few macro-level studies focusing on situational and environmental factors, which can be considered a severe gap in the existing literature. It could thus be concluded that organization-level aspects have dominated the discourse, whereas individual, group, and macro-level aspects have aroused relatively marginal interest among scholars. This is somewhat logical as well: after all, the discourse is about organizational creativity. However, this fact should not mean that the other aspects affecting organizational creativity, including individual, group, and macro-level factors, should be ignored. Accordingly, scholars should study these aspects of organizational creativity more actively in the future.

The domination of drivers and the scarcity of barriers are apparent at each level of analysis. It is understandable that drivers of organizational creativity are more attractive as a topic of study than barriers. However, in general, equal attention should be given to both, especially because of the human tendency to give more weight to negative than positive issues (cf. Baumeister et al., 2001). Therefore, a small number of barriers may effectively inhibit creativity regardless of the effort expended toward factors that are considered to enhance creativity. Moreover, the review indicates an apparent tendency to dichotomize the factors influencing organizational creativity. In other words, it is typical for the organizational creativity discourse to discuss the antecedents of creativity exclusively from the viewpoint of drivers. In some cases, the antecedents were discussed from the perspective of being barriers, but only rarely was it recognized that the same factor may either enhance or inhibit creativity. Accordingly, in the case of these so-called either-or factors, i.e., factors working potentially either as drivers or as barriers, in future scholars should recognize both aspects and make them explicit in their analyses.

In a similar vein, there is a need for research on the mutual relationships among onedirectional factors or factors that are theoretically either drivers or barriers. The general rule of the thumb would suggest that the presence of a greater number of drivers and fewer barriers in an organization is favorable for organizational creativity. However, it might be interesting to study whether it is possible, for instance, to enhance organizational creativity by increasing the number of (certain) drivers without removing (certain) barriers first. If it is, which drivers/barriers are affected, in what kinds of situations, and to what extent? These kinds of questions obviously open the door to numerous pragmatic questions regarding organizational creativity that should be addressed by further research.

This review potentially provides important managerial implications. For example, however appealing it is to encourage and promote creativity by various means, it is equally important to make sure that the potential inhibitors of organizational creativity are also dealt with. In other words, managers should pay attention not just to drivers but also to barriers in facilitating organizational creativity. Therefore, management should be very careful with any potential barriers of creativity because, for instance, a discouraging/ignorant attitude or comment from a manager may easily overcome good attempts to encourage creativity in the organization (cf. Baumeister et al., 2001). Moreover, recognizing the fact that many antecedents of organizational creativity are either-or factors is essential for managers interested in creativity. Doing so would 
allow managers to acknowledge that the very same factors may enhance or inhibit creativity and help them in assessing when, how, and under which circumstances a barrier might act as a driver and vice versa. Thus, understanding the paradoxical nature and influence of many antecedents of organizational creativity (cf. Andriopoulos and Lewis, 2010) might provide managers conceptual tools, which could be helpful in enhancing organizational creativity.

This paper also has some limitations. First, although we used three important databases in the field of business and management, the initial database search or the selection of articles for further analysis might have omitted some relevant work. We have, however, attempted to avoid this by having two of the authors read all the article abstracts and collectively decide whether to select the articles for further analysis. Also, the snowballing technique was used to increase the probability of including all relevant work. Second, one obvious limitation of this paper relates to its aim, which was to review antecedents of organizational creativity, necessarily excluding other perspectives and theories regarding organizational creativity. However, to present a more balanced overview of the topic, the main theories and perspectives are briefly discussed in this paper. Third, a central limitation of this review is that it relies primarily on a keyword search. This means that studies discussing creativity but using another concept, such as innovation, research and development, organizational change, or organizational renewal were likely to have been excluded from the review. The snowball search probably compensated for this at least to some extent, but something relevant might have been omitted. This limitation is not exclusive to this review, but is a common challenge in all academic writing as it is difficult to draw exact lines between what belongs to a certain academic discourse and what does not. Therefore, it is reasonable to assume that this paper provides a comprehensive and topical review of antecedents of organizational creativity and that any research excluded or omitted from the review would not have changed the main arguments and conclusions.

Drivers and barriers are clearly an important topic in the field of organizational creativity. However, even though new studies are emerging at a higher rate than ever before, on the basis of this review, it is fair to say that only the surface has been scratched - perhaps excluding organization-level drivers, which have been studied extensively. We hope that this review will provide scholars with new ideas and insights into how to approach the antecedents of organizational creativity in future studies.

\section{$7 \quad$ Endnotes}

1. In this paper, the concept of discourse refers to structured collections of related texts that denote certain ways to address a particular phenomenon (cf. Hardy and Phillips, 2004, p. 299).

2. The databases were: ABI/Inform (ProQuest) Global, Business Source Complete (EBSCO), and Emerald Journals (Emerald).

3. The search phrase stipulates that both the word 'organization' or its British version 'organisation' and the word 'creativity' appear in the abstract or the 
citation/keyword field, and/or in the title of the article. In addition, the '*' symbol was used for multiple character wildcard searches, so that it looks for 0 or more characters. This meant that the search included words such as organizations, organization, and organizational. (see Blomberg, 2014.)

4. While Woodman et al. (1993) use the term 'contextual influences', in this paper we prefer the term 'macro', as we discuss the different levels of organizational creativity.

\section{$8 \quad$ References}

Adler, P.S. \& Obstfeld, D. (2007). The role of affect in creative projects and exploratory search. Industrial and Corporate Change, 16(1), 19-50.

Ahmed, P.K. (1998). Culture and climate for innovation. European Journal of Innovation Management, 1(1), 30-43.

Al-Beraidi, A. \& Rickards, T. (2003). Creative team climate in an international accounting office: An exploratory study in Saudi Arabia. Managerial Auditing Journal, 18(1), 7-18.

Al-Beraidi, A. \& Rickards, T. (2007). The role of affect in creative projects and exploratory search. Industrial and Corporate Change, 16(1), 19-50.

Amabile, T.M. (1983). The social psychology of creativity: A componential conceptualization. Journal of Personality and Social Psychology, 45(2), 357377.

Amabile, T.M. (1988). A model of creativity and innovation in organizations. In Staw, BM and Cumming LL (eds.), Research in Organizational Behavior 10, 123-169. Greenwich: J.A.I. Press.

Amabile, T.M. (1996). Creativity in Context. Boulder, CO: Westview Press.

Amabile, T.M. (1997). Motivating creativity in organizations: On doing what you love and loving what you do. California Management Review, 40(1), 39-58.

Amabile, T. M., Conti, R., Coon, H., Lazenby, J. \& Herron, M (1996). Assessing the work environment for creativity. Academy of Management Journal, 39(5), 1154-1184.

Amabile, T.M, Barsade, S., Mueller, J. \& Staw, B. (2005). Affect and creativity at work. Administrative Science Quarterly, 50(3), 367-403.

Amabile, T.M, Hadley, C.N., \& Kramer, S.J. (2002). Creativity under the gun. Harvard Business Review, 80(8), 52-61.

Amar A.D. \& Juneja, J.A (2008). A descriptive model of innovation and creativity in organizations: A synthesis of research and practice. Knowledge Management Research and Practice, 6(4), 298-311.

Andersen, J. (2000). Intuition in managers: Are intuitive managers more effective. Journal of Managerial Psychology, 15(1), 46-63.

Andersen, P.H \& Kragh, H. (2015). Exploring boundary-spanning practices among creativity managers. Management Decision, 53(4), 786-808. 
Anderson, N., Potočnik, K., \& Zhou, J. (2014). Innovation and creativity in organizations: A state-of-the-science review, prospective commentary, and guiding framework. Journal of Management, 40(5), 1297-1333.

Andriopoulos, C. (2001). Determinants of organizational creativity: A literature review. Management Decision, 39(10), 834-840.

Andriopoulos, C. (2003). Six paradoxes in managing creativity. Long Range Planning, 36(4), 375-388.

Andriopoulos, C. \& Lewis, M. W. (2010). Managing innovation paradoxes: Ambidexterity lessons from leading product design companies. Long Range Planning, 43(1), 104-122.

Andriopoulos, C. \& Gotsi, M. (2000). Benchmarking brand management in the creative industry. Benchmarking: An International Journal, 7(5), 360-372.

Andriopoulos, C. \& Gotsi, M. (2005). The virtues of "Blue Sky" projects: How lunar design taps into the power of imagination. Creativity and Innovation Management, 14(3), 316-324.

Axtell, C.M., Holman, D.J., Unsworth, K.L., Wall, T.D. \& Waterson, P.E. (2000). Shopfloor innovation: Facilitating the suggestion and implementation ideas. Journal of Occupational and Organizational Psychology, 73(3), 265-385.

Baer, M., Oldham, G. R. \& Cummings, A. (2003). Rewarding creativity: When does it really matter? The Leadership Quarterly, 14(4-5), 569-586.

Baer, M. \& Oldham, G. R. (2006). The curvilinear relation between experienced creative time pressure and creativity: Moderating effects of openness to experience and support for creativity. Journal of Applied Psychology, 91(4), 963-970.

Baron, R.A. \& Tang, J. (2011). The role of entrepreneurs in firm-level innovation: Joint effects of positive affect, creativity, and environmental dynamism. Journal of Business Venturing, 26(1), 49-60.

Barrett, H., Balloun, J. \& Weinstein, A. (2005). The impact of creativity on performance in non-profits. International Journal of Nonprofit and Voluntary Sector Marketing, 10(4), 213-223.

Basadur, M. \& Gelade, G.A. (2006). The role of knowledge management in the innovation process. Creativity and Innovation Management, 15(1), 45-62.

Bassett-Jones, N. (2005). The paradox of diversity management, creativity and innovation. Creativity and Innovation Management, 14(2), 169-175.

Baumeister, R., Bratslavsky, E., Finkenauer, C., \& Vohs, K. (2001). Bad is stronger than good. Review of General Psychology, 5(4), 323-370.

Baycan-Levent, T. (2010). Diversity and creativity as seedbeds for urban and regional dynamics. European Planning Studies, 18(4), 565-594.

Bharadwaj, S. \& Menon, A. (2000). Making innovation happen in organizations: Individual creativity mechanisms, organizational creativity mechanisms or both? Journal of Product Innovation Management, 17(6), 424-34.

Birdi, K. (2005). No idea? Evaluating the effectiveness of creativity training. Journal of European Industrial Training, 29(2), 102-111. 
Bissola, R. \& Imperatori, B. (2011). Organizing individual and collective creativity: Flying in the face of creativity clichés. Creativity and Innovation Management, 20(2), 77-89.

Björkman, H. (2004). Design dialogue groups as a source of innovation: Factors behind group creativity. Creativity and Innovation Management, 13(2), 97-108.

Blomberg, A. (2014). Organizational creativity diluted: A critical appraisal of discursive practices in academic research. Journal of Organizational Change Management, 27(6), 935-954.

Borghini, S. (2005). Organizational creativity: Breaking equilibrium and order to innovate. Journal of Knowledge Management, 9(4), 19-33.

Braun, V. \& Clarke, V. (2006). Using thematic analysis in psychology. Qualitative Research in Psychology, 3, 77-101.

Brown, A. D., Kornberger, M., Clegg, S. R. \& Carter, C. (2010). 'Invisible Walls' and 'Silent Hierarchies': A case study of power relations in an architecture firm. Human Relations, 63(4), 525-549.

Bunduchi, R. (2009). Implementing best practices to support creativity in NPD crossfunctional teams. International Journal of Innovation Management, 13(4), 537554.

Burbiel, J. (2009). Creativity in Research and Development environments: A practical review. International Journal of Business Science and Applied Management, 4(2), 35-51.

Butler, S. (2010). Solving business problems using a lateral thinking approach. Management Decision, 48(1), 58-64.

Castiglione, J. (2008). Facilitating employee creativity in the library environment. Library Management, 29(3), 159-172.

Castro, F., Gomes, J. \& de Sousa, F. C. (2012). Do intelligent leaders make a difference? The effect of a leader's emotional intelligence on followers' creativity. Creativity and Innovation Management, 21(2), 171-182.

Chamakiotis, P., Dekoninck, E. A. \& Panteli, N. (2013). Factors influencing creativity in virtual design teams: An interplay between technology, teams and individuals. Creativity and Innovation Management, 22(3), 265-279.

Chang, W.C. \& Chiang, Z.H. (2008). A study on how to elevate organisational creativity in Taiwanese design organisation. International Journal of Innovation Management, 12(4), 699-723.

Chong, E. \& Ma, X. (2010). The influence of individual factors, supervision and work environment on creative self-efficacy. Creativity and Innovation Management, 19(3), 233-247.

Christensen, K.S. (2006). Losing innovativeness: The challenge of being acquired. Management Decision, 44(9), 1161-1182.

Çokpekin, Ö. \& Knudsen, M. P. (2012). Does organizing for creativity really lead to innovation? Creativity and Innovation Management, 21(3), 304-314.

Cooper, P. (2005). A study of innovators' experience of New Product Innovation in organisations. $R \& D$ Management, 35(5), 525-533. 
Cropley, D. \& Cropley, A.J. (2013). Creativity and Crime: A Psychological Analysis. Cambridge: Cambridge University Press.

Crossan, M. \& Apaydin, M. (2010). A multi-dimensional framework of organizational innovation: A systematic review of the literature. Journal of Management Studies, 47(6), 1154-1191.

Csikszentmihalyi, M. (1994). The domain of creativity. In Feldman DH, Csikszentmihalyi M and Gardner H (eds.), Changing the World: A Framework of the Study of Creativity. 135-158. Westport, CT: Praeger.

Daymon, C. (2000). Cultivating creativity in Public Relations Consultancies: The management and organization of creative work. Journal of Communication Management, 5(1), 17-30.

De Stobbeleir, M., Ashford, S. \& Buyens, D. (2011). Self-regulation of creativity at work: The role of feedback-seeking behavior in creative performance. Academy of Management Journal, 54(4), 811-831.

DiLiello, T. \& Houghton, J. (2008). Creative potential and practiced creativity: Identifying untapped creativity in organizations. Creativity and Innovation Management, 17(1), 37-46.

Egan, T. (2005). Creativity in the context of team diversity: Team leader perspectives. Advances in Developing Human Resources, 7(2), 207-225.

Ejaz, W., Shah, S., Saad, H., Aziz, J., Jaffari, A.R., Zaman, A. \& Jaffari, M.R (2011). Role of self concordant goals in obtaining innovation and creativity in the employees. Interdisciplinary Journal of Contemporary Research in Business, 3(4), 172-181.

Elsbach, K. \& Hargadon, A (2006). Enhancing creativity through "mindless" work: A framework of workday design. Organization Science, 17(4), 470-483.

Epstein, R., Kaminaka, K., Phan, V. \& Uda, R. (2013). How is creativity best managed? Some empirical and theoretical guidelines. Creativity and Innovation Management, 22(4), 359-374.

Erez, M. \& Nouri*, R. (2010). Creativity: The influence of cultural, social, and work contexts. Management and Organization Review, 6(3), 351-370.

Farmer, S., Tierney, P. \& Kung-McIntyre, K. (2003). Employee creativity in Taiwan: An application of role identity theory. Academy of Management Journal, 46(5), 618-630.

Ford, C.M. (1996). A theory of individual creative action in multiple social domains. Academy of Management Review, 21(4), 1112-1142.

George, J. M. \& Zhou, J. (2002). Understanding when bad moods foster creativity and good ones don't: The role of context and clarity of feelings. Journal of Applied Psychology, 87(4), 687-697.

George, J. M. \& Zhou, J. (2007). Dual tuning in a supportive context: Joint contributions of positive mood, negative mood, and supervisory behaviors to employee creativity. Academy of Management Journal, 50(3), 605-622.

Goldenberg, J., \& Mazursky, D. (2008). When deep structures surface: Design structures that can repeatedly surprise. Journal of Advertising, 37(4), 21-34. 
Griffin, A., Price, R., Maloney, M., Vojak, B. \& Slim, E. (2009). Voices from the field: How exceptional electronic industrial innovators innovate. Journal of Product Innovation Management, 26(2), 222-240.

Haner, U-E. (2005). Spaces for creativity and innovation in two established organizations. Creativity and Innovation Management, 14(3), 288-298.

Hardy, C. \& Phillips, N. (2004). Discourse and Power. In D. Grant, C. Hardy, C. Oswick and L. Putnam (eds.) The SAGE Handbook of Organizational Discourse, (pp. 299-316). Thousand Oaks, CA: Sage.

He, Y., Ding, X.-H. \& Yang, K. (2014). Unpacking the relationships between conflicts and team innovation: Empirical evidence from China. Management Decision, 52(8), 1533-1548.

Hemlin, S. (2009). Creative knowledge environments: An interview study with group members and group leaders of University and Industry R\&D groups in biotechnology. Creativity and Innovation Management, 18(4), 278-285.

Hempel, P. S. \& Sue-Chan, C. (2010). Culture and the assessment of creativity. Management and Organization Review, 6(3), 415-435.

Isaksen, S. \& Ekvall, G. (2010). Managing for innovation: The two faces of tension in creative climates. Creativity and Innovation Management, 19(2), 73-88.

Isaksen, S. \& Lauer, K. (2002). The climate for creativity and change in teams. Creativity and Innovation Management, 11(1), 74-87.

Jesson, J.K., Matheson, L. \& Lacey, F.M. (2011). Doing Your Literature Review. Traditional and Systematic Techniques. London: Sage.

Kessel, M., Kratzer, J. \& Schultz, C. (2012). Psychological safety, knowledge sharing, and creative performance in healthcare teams. Creativity and Innovation Management, 21(2), 147-157.

Khandwalla, P.N. \& Mehta, K (2004). Design of corporate creativity. Vikalpa: The Journal for Decision Makers, 29(1), 13-28.

Klijn, M. \& Tomic, W. (2010). A review of creativity within organizations from a psychological perspective. The Journal of Management Development, 29(4), 322-343.

Knight, E. \& Harvey, W. (2015). Managing exploration and exploitation paradoxes in creative organisations. Management Decision, 53(4), 809-827.

Kylén, S.F. \& Shani, A.B. (Rami) (2002). Triggering creativity in teams: An exploratory investigation. Creativity and Innovation Management, 11(1), 17-31.

Lang, J \& Lee, C. (2010). Workplace humor and organizational creativity. Journal of Human Resource Management, 21(1), 46-60.

Lapierre, J. \& Giroux, V-P. (2003). Creativity and work environment in a high-tech context. Creativity and Innovation Management, 12(1), 11-23.

Lewis, M.W. (2000). Exploring paradox: Toward a more comprehensive guide. Academy of Management Review, 25(4), 760-776.

Litchfield, R. (2008). Brainstorming reconsidered: A goal-based view. Academy of Management Review, 33(3), 649-668. 
Lucarelli, A. \& Berg, P.O. (2011). City branding: A state-of-the-art review of the research domain. Journal of Place Management and Development, 4(1), 9-27.

Madjar, N. (2005). The contributions of different groups of individuals to employees' creativity. Advances in Developing Human Resources, 7(2), 182-206.

Madjar, N. (2008). Emotional and informational support from different sources and employee creativity. Journal of Occupational Organizational Psychology, 81(1), $83-100$.

Madjar, N. \& Ortiz-Walters, R (2008). Customer as contributors and reliable evaluators of creativity in the service industry. Journal of Organizational Behavior, 29, 949-966.

Magadley, W. \& Birdi, K. (2009). Innovation labs: An examination into the use of physical spaces to enhance organizational creativity. Creativity and Innovation Management, 18(4), 315-325.

Mahmoud-Jouini, S.B. \& Charue-Duboc, F. (2008). Enhancing discontinuous innovation through knowledge combination: The case of an exploratory unit within an established automotive firm. Creativity and Innovation Management, 17(2), 127-135.

Mainemelis, C. (2010). Stealing fire: Creative deviance in the evolution of new ideas. Academy of Management Review, 35(4), 558-578.

Martens, Y. (2011). Creative workplace: Instrumental and symbolic support for creativity. Facilities, 29(1-2), 63-79.

Martins, E.C. \& Terblanche, F. (2003). Building organisational culture that stimulates creativity and innovation. European Journal of Innovation Management, 6(1), 64-74.

Mathisen, G.E. (2011). Organizational antecedents of creative self-efficacy. Creativity and Innovation Management, 20(3), 185-195.

Mathisen, G. E., Einarsen, S. \& Mykletun, R. (2012). Creative leaders promote creative organizations. International Journal of Manpower, 33(4), 367-382.

McFadzean, E. (2000). Techniques to enhance thinking. Team Performance Management, 6(3), 62-72.

McLean, L.D. (2005). Organizational culture's influence on creativity and innovation: A review of the literature and implications for human resource development. Advances in Developing Human Resources, 7(2), 226-246.

Misra, S. (2011). R\&D team creativity: A way to team innovation. International Journal of Business Insights and Transformation, 4(2), 31-36.

Mintzberg, H. (1979) The Structuring of Organizations. Upper Saddle River, US: Prentice-Hall.

Mohamed, M.Z. \& Rickards, T. (1996). Assessing and comparing the innovativeness and creative climate of firms. Scandinavian Journal of Management, 12(2), 109121.

Morris, M. W. \& Leung, K. (2010). Creativity East and West: Perspectives and parallels. Management and Organization Review, 6(3), 313-327. 
Morgan, G. (1986) Images of Organization. Thousand Oaks, US: Sage.

Mostafa, M. (2005). Factors affecting organizational creativity and innovativeness in Egyptian business organizations: An empirical investigation. The Journal of Management Development, 24(1), 7-33.

Mostafa, M. \& El-Masry, A. (2008). Perceived barriers to organizational creativity. A cross-cultural study of British and Egyptian future Marketing Managers. Cross Cultural Management: An International Journal, 15(1), 81-93.

Moultrie, J. \& Young, A. (2009). Exploratory study of organizational creativity in creative organizations. Creativity and Innovation Management, 18(4), 299-314.

Mumford, M. (2000). Managing creative people: Strategies and tactics for innovation. Human Resource Management Review, 10(3), 313-352.

Oldham, G.R. \& Cummings, A. (1996). Employee creativity: Personal and contextual factors at work. Academy of Management Journal, 39, 607-634.

Pech, R.J. (2001). Reflections: Termites, group behaviour, and the loss of innovation: Conformity rules!" Journal of Managerial Psychology, 16(7), 559-574.

Perry-Smith, J. (2006). Social yet creative: The role of social relationships in facilitating individual creativity. Academy of Management Journal, 49(1), 85101.

Politis, J.D. (2005). Dispersed leadership predictor of the work environment for creativity and productivity. European Journal of Innovation Management, 8(2), 182-204.

Pryor, M.G., Singleton, L.P., Taneja, S. \& Toombs, L.A. (2010). The 4R's model for nurturing creative talent. International Journal of Business and Public Administration, 7(1), 27-39.

Rego, A., Sousa, F., Pina e Cunha, M., Correia, A. \& Saur-Amaral, I. (2007). Leader self-reported emotional intelligence and perceived employee creativity: An exploratory study. Creativity and Innovation Management, 16(3), 250-264.

Richter, A. W., Hirst, G., van Knippenberg, D, \& Baer, M (2012). Creative selfefficacy and individual creativity in team contexts: Cross-level interactions with team informational resources. Journal of Applied Psychology, 97(6), 12821290 .

Ridley, D. (2012). The Literature Review: A Step-by-Step Guide for Students. London, UK: Sage.

Sadi, M.A. \& Al-Dubaisi, A.H. (2008). Barriers to organizational creativity. The Marketing Executives' perspective in Saudi Arabia. Journal of Management Development, 27(6), 574-599.

Sailer, K. (2011). Creativity as social and spatial process. Facilities, 29(1-2), 6-18.

Saunders, M., Lewis, P. \& Thornhill, A. (2003). Research Methods for Business Students. Essex, UK: Prentice Hall.

Schepers, P. \& Berg, P. (2006). Social factors of work-environment creativity. Journal of Business and Psychology, 21(3), 407-428.

Shahin, A. \& Zeinali, Z. (2010). Developing a relationship matrix for organizational 
learning and innovativeness: With a case study in a manufacturing company. International Journal of Business and Management, 5(7), 187-203.

Shalley, C.E. \& Zhou, J. (2008). Organizational creativity research: A historical overview. In Zhou J and Shalley CE (eds.), Handbook of Organizational Creativity, 3-31. London, UK: Taylor \& Francis.

Shin, S. J. \& Zhou, J. (2003). Transformational leadership, conservation, and creativity: Evidence from Korea. Academy of Management Journal, 46(6), 703714.

Sohn, S. \& Jung, C. (2010). Effect of creativity on innovation: Do creativity initiatives have significant impact on innovative performance in Korean firms? Creativity Research Journal, 22(3), 320-328.

Somech, A. (2006). The effects of leadership style and team process on performance and innovation in functionally heterogeneous teams. Journal of Management, 32(1), 132-157.

Styhre, A. \& Sundgren, M. (2005). Managing Creativity in Organizations. Critique and Practices. Macmillan, New York: Palgrave.

Sundgren, M. \& Styhre, A. (2007). Creativity and the fallacy of misplaced concreteness in new drug development. A Whiteheadian perspective. European Journal of Innovation Management, 10(2), 215-235.

Sundgren, M., Dimenäs, E., Gustafsson, J-E. \& Selart, M. (2005). Drivers of organizational creativity: a path model of creative climate in pharmaceutical R\&D. R\&D Management, 35(4), 359-374.

Sundgren, M., Selart, M., Ingelgård, A. \& Bengtson, K. (2005). Dialogue-based evaluation as a creative climate indicator: Evidence from the pharmaceutical industry. Creativity and Innovation Management, 14(1), 84-98.

Tajeddini, K. (2009). The impact of learning orientation on NSD and hotel performance: Evidence from the hotel industry in Iran. Education, Business and Society: Contemporary Middle Eastern Issues, 2(4), 262-275.

Tetenbaum, T.J. (1998). Shifting paradigms: From Newton to chaos. Organizational Dynamics, 26(4), 21-32.

Thompson, L. (2003). Improving the creativity of organizational work group. Academy of Management Executive, 17(1), 96-109.

Tierney, P. \& Farmer, S. M. (2002). Creative self-efficacy: Its potential antecedents and relationship to creative performance. Academy of Management Journal, 45(6), 1137-1148.

Tierney, P. \& Farmer, S. M. (2011). Creative self-efficacy development and creative performance over time. Journal of Applied Psychology, 96(2), 277-293.

Umemoto, K., Endo, A. \& Machado, M. (2004). From Sashimi to Zen-In: The evolution of concurrent engineering at Fuji Xerox. Journal of Knowledge Management, 8(4), 89-99.

Unsworth, K.L. \& Clegg, C.W. (2010). Why do employees undertake creative action?. Journal of Occupational and Organizational Psychology, 83(1), 77-99.

Wang, K.Y. \& Casimir, G. (2010). Why do employees undertake creative action? 
Walton, A. (2003). The impact of interpersonal factors on creativity. International Journal of Entrepreneurial Behaviour and Research, 9(4), 146-162.

Wang, K.Y. \& Casimir, G. (2007). How attitudes of leaders may enhance organizational creativity: Evidence from a Chinese study. Creativity and Innovation Management, 16(3), 229-238.

Wang, P. \& Rode, J. C. (2010). Transformational Leadership and Follower Creativity: The Moderating Effects of Identification with Leader and Organizational Climate. Human Relations, 63(8), 1105-1128.

Weisberg, R.W. (1999). Creativity and Knowledge: A Challenge to Theories. In Stembeig RJ (eds.), Handbook of Creativity, 226-250. New York, NY: Cambridge University Press.

West, M (2004). Motivate Teams, Maximize Success: Effective Strategies for Realizing Your Goals. San Francisco, CA: Chronicle Books.

Williams, S.D. (2002). Self-esteem and the self-censorship of creative ideas. Personnel Review, 31(4), 495-503.

Wood, R, Franzak, F., Pitta, D. \& Gillpatrick T. (2011). Integrating creative people, creative communities and macro-environmental characteristics into the marketing organization. Journal of Marketing Development and Competitiveness, 5(3), 32-46.

Woodman, RW, Sawyer, J.E. \& Griffin, R.W. (1993). Towards a Theory of Organizational Creativity. Academy of Management Review, 18(2), 293-321.

Yoon, S., Song, J. Lim, D. H. \& Joo, B.-K. (2010). Structural determinants of team performance: The mutual influences of learning culture, creativity, and knowledge. Human Resource Development International, 13(3), 249-264.

Zhou, J (1998). Feedback valence, feedback style, task autonomy, and achievement orientation: Interactive effects on creative performance. Journal of Applied Psychology, 83(2), 261-276.

Zhou, J \& George, J. (2001). When job dissatisfaction leads to creativity: Encouraging the expression of voice. Academy of Management Journal, 44(4), 682-696.

Zhou, J \& George, J.M. (2003). Awakening employee creativity: The role of leader emotional intelligence. The Leadership Quarterly, 14(4-5), 545-568.

Zhou, J, Shin, S.J. \& Cannella, A. (2008). Employee self-perceived creativity after Mergers and Acquisitions: Interactive effects of threat-opportunity perception, access to resources, and support for creativity. The Journal of Applied Behavioral Science, 44(4), 397-421.

Zhou, J \& Su, Y. (2010). A missing piece of the puzzle: The organizational context in cultural patterns of creativity. Management and Organization Review, 6(3), 391413. 
Appendix 1 Growth in number of documents mentioning organizational creativity

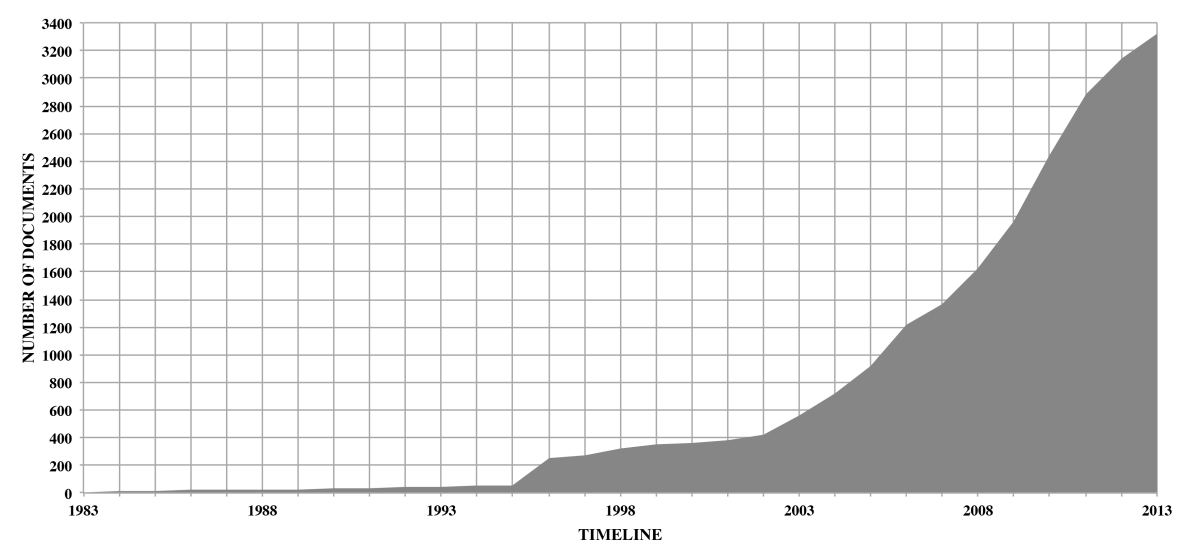

